\title{
Trabalho emocional e gênero: dimensões do trabalho no Serviço Social
}

Emotional labor and gender: dimensions of labor in Social Work Débora de Paula Bolzan*

\begin{abstract}
Resumo - Este resumo analisa o trabalho emocional de assistentes sociais, tomando como base uma pesquisa de mestrado desenvolvida na região metropolitana de Goiânia (GO). Para tanto, propõe uma discussão da temática, pouco conhecida no Serviço Social, e traça o objetivo de identificar como a apropriação do trabalho emocional é feita nessa profissão. Os resultados apontam que a gestão emocional é uma das diferentes dimensões e exigências do trabalho no Serviço Social e identificam que assistentes sociais vivenciam e gerenciam emoções, em grau considerável, e alteram o gerenciamento emocional nas diferentes demandas, competências e situações relacionadas à profissão. Não obstante, verificou-se que o trabalho no Serviço Social envolve uma interseção intrínseca a gênero, configurando o trabalho das emoções como sexuado e constitutivo do processo de construção da identidade profissional.

Palavras-chave: Serviço Social; trabalho emocional; gênero; setor de serviços.
\end{abstract}

\begin{abstract}
This summary examines the emotional labor of social workers, based on a Masters level study developed in the metropolitan area of Goiânia, Goiás. With this aim, it proposes a discussion about this concept, rarely seen in Social Work literature, attempting to identify how emotional labor is realized and managed in this profession. The results show that emotional management is one of the various dimensions and requirements of the job in Social Work and indicate that social workers do experience emotions, to a considerable degree, and alter the emotional management in the different demands, skills and situations related to the profession. Nevertheless, Social Work involves an intrinsic gender intersection, taking the gendered emotional labor as constitutive of the very construction of professional identity.
\end{abstract}

Keywords: Social Work; emotional labor; gender; services sector.

\footnotetext{
* Assistente social graduada pela Universidade Federal do Espírito Santo (UFES), mestra em Sociologia pela Universidade Federal de Goiás (UFG). Professora de Serviço Social da Universidade Federal do Tocantins (UFT). Correspondência: Universidade Federal do Tocantins - Av. Lourdes Solino, S/N, Setor Universitário, CEP: 77.000000, Miracema/TO. Email: <debora.bolzan@uft.edu.br>
} 


\section{Introdução}

As emoções fazem parte de toda a história da vida humana; no entanto, constituíram-se como novo campo de estudos somente na década 1970. Este campo foi resultado de um processo de renovação teórica iniciado nos Estados Unidos, que promoveu uma releitura da tradição sociológica e antropológica, contribuindo para o surgimento da sociologia e da antropologia das emoções como novas disciplinas. Assim, situando as emoções como uma importante categoria para a reflexão da inter-relação entre indivíduo e sociedade (KOURY, 2014). Esta nova abordagem recorreu, principalmente, à filosofia francesa de Derrida e Foucault e à filosofia social de Simmel, entre outros autores.

Naquele país, o campo das emoções conheceu um forte desenvolvimento a partir de meados dos anos 1980, com uma diversidade de pesquisas e publicações, como a desenvolvida por Lutz (1990), ao refletir sobre o lugar da emoção no pensamento do Ocidente. A autora identificou um discurso ocidental associando as emoções ao gênero feminino, ou seja, as emoções vistas como sinais de fraqueza e voltadas à mulher, ao contrário da racionalidade, relacionada ao homem (LUTZ, 1990).

Ainda no contexto norte-americano dos anos 1980, Arlie Hochschild (1983), embasada na perspectiva dramatúrgica de Goffman (1959), tornou-se uma grande referência na sociologia das emoções ao definir o conceito de trabalho emocional (TE). Este pode ser compreendido como a gestão das emoções ou a atuação da pessoa sobre os sentimentos, no trabalho, para produzir um resultado em si mesmo e nos outros, criando uma expressão facial e corporal observável e desejada pela organização. Isso significa que no TE é necessário administrar e articular mente e sentimentos, além dos trabalhos físicos e mentais já inerentes às tarefas desempenhadas neste ambiente.

Desde que o conceito de trabalho emocional foi formulado por Hochschild (1983), passou a orientar diversas pesquisas no Ocidente. Valquíria Padilha (2013) registra a publicação de mais de 300 artigos empregando o conceito de TE, o que indica que este tema se encontra em intenso debate em diferentes países.

No contexto brasileiro, a temática ganha reconhecimento e consolidação quase duas décadas depois, nos anos 1990 (KOURY, 2014). O interesse por ela tem contribuído para a discussão sobre as emoções no consumo (ALMEIDA; NIQUE, 2004), nas compras on-line (COSTA; FARIAS, 2004) e nas mais diversas profissões (PADILHA, 2013; NUNES, 2011; VILELA; ASSUNÇÃO, 2007). Dessa maneira, estimula grupos de pesquisa, como o Grupo de Pesquisa em Antropologia e Sociologia da Emoção (Grem), da Universidade Federal da Paraíba, fundado em 1994 e liderado por Mauro Koury, um dos primeiros brasileiros a realizar reflexões sociológicas e pesquisas sobre as emoções. Este grupo produz o periódico acadêmico intitu- 


\section{ReVistg a}

\} TRABALHO EMOCIONAL E GÊNERO - BOLZAN, D. P.

DOI: $10.12957 /$ rep.2015.21054

lado Revista Brasileira de Sociologia das Emoções, trazendo abordagens e contribuições aos campos da sociologia e da antropologia das emoções. Além disso, há, desde 1998, o Grupo de Pesquisa Transformações da Intimidade, da Universidade Estadual do Rio de Janeiro (Uerj), e o Grupo de Pesquisa Cultura, Sociabilidades e Sensibilidades Urbanas, instituído desde 2010 na Universidade Federal da Bahia.

No ambiente de trabalho, em especial no setor de serviços ${ }^{1}$, espera-se a demonstração de emoções que muitas vezes não existem. Desta maneira, os trabalhadores devem possuir a capacidade de desenvolver a gestão dos seus próprios sentimentos para serem capazes de realizar o trabaIho e expressar emoções, como sorrir e ser cordial, mesmo sem vontade de fazê-lo. É o que se espera, por exemplo, do trabalho de recepcionista de hipermercado, dos operadores de caixa, comissários de bordo em linhas aéreas e em diversas profissões do setor de serviços (HOCHSCHILD, 1983).

Este setor representa, por excelência, a ocupação laboral feminina no mercado de trabalho, sendo marcado por interações que exigem novas formas de controle, de gerenciamento e de administração das emoções constituídas nessas interações (SORJ, 2000). De acordo com Hochschild (1983), o trabalho emocional em serviços envolve um componente altamente sexuado, apresentando um caráter fortemente ligado a atributos construídos socialmente como femininos. Assim, a análise do trabalho emocional no Serviço Social torna imprescindível um viés de gênero ${ }^{2}$, uma vez que o Serviço Social está entre as profissões brasileiras que mais empregam muIheres.

Na década de 1970, o Serviço Social era a segunda profissão com maior concentração de mulheres no país; nos censos de 1980, 1991 e 2000 foi assumido como a profissão de nível superior mais feminina do Brasil (SIMÕES, 2012). Desse modo, Serviço Social, Enfermagem, Pedagogia e Biblioteconomia são as quatro profissões mais influenciadas pelo gênero no mercado de trabalho brasileiro. Tais profissões revelam que as desigualdades entre os gêneros persistem historicamente e posicionam a mulher em uma situação desigual, construída a partir da divisão sexual ${ }^{3}$ do trabalho e que ganha concretude no mercado de trabalho, sobretudo no setor de serviços (SORJ, 2000). Nesse contexto, o trabalho no Serviço Social apresenta particularidades, principalmente porque a atividade é constituída por

\footnotetext{
${ }^{1}$ A distinção habitual entre atividades econômicas compreende os tradicionais setores: primário (agrícola, pesca, caça e extrativismo), secundário (industrial) e terciário (serviços). Entre estes, lista-se: comércio; transportes; publicidade; computação; telecomunicações; educação; saúde; setor financeiro, bancário e de seguros; administração pública; alimentação; manutenção e reparação; beleza e higiene; diversões e recreação etc.

${ }^{2} \mathrm{~A}$ análise da categoria gênero deve ser entendida como uma relação entre sujeitos históricos e participantes de um padrão de acumulação capitalista. Este apropria-se das relações de gênero para explorar as diferenças socialmente construídas a seu favor. Assim, "os sujeitos históricos têm suas relações reguladas pelo gênero, conjunto de representações absolutamente central na sociedade" (SAFFIOTI, 2004, p. 74).

${ }^{3} \mathrm{O}$ conceito refere-se à distribuição desigual de homens e mulheres no mundo do trabalho, nas profissões e na divisão desigual do trabalho doméstico. Essa divisão varia no tempo e no espaço, hierarquizando atividades, valorizando ou não certas profissões e criando "guetos" ocupacionais, como é o caso do Serviço Social. Ver: Lobo, 1991.
} 


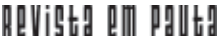

\} TRABALHO EMOCIONAL E GÊNERO - BOLZAN, D. P. \}

DOI: $10.12957 /$ rep.2015.21054

marcadores de desigualdade: é uma profissão historicamente feminizada, instalada no setor de serviços e que não ocupa lugar de destaque na hierarquia das profissões. Portanto, torna-se importante identificar como a apropriação do trabalho emocional é feita no Serviço Social.

\section{Dados da pesquisa}

A pesquisa ${ }^{4}$ ora apresentada analisou o trabalho emocional como uma das diferentes dimensões e exigências do trabalho no Serviço Social. Para tanto, propôs uma discussão da temática, pouco conhecida no Serviço Social, e traçou o objetivo de identificar como a apropriação do trabalho emocional é feita nessa profissão.

A metodologia ${ }^{5}$ privilegiou as abordagens qualitativas, com base em levantamento de literatura pertinente, análise documental e observação sistemática. A pesquisa de campo envolveu a realização de entrevistas semiestruturadas, utilizando elementos técnicos de entrevistas narrativas (FLICK, 2004) com os assistentes sociais da região metropolitana de Goiânia (GO). As narrativas objetivam obter experiências mais subjetivas e dados de maior profundidade do que nos relatos da entrevista semiestruturada (FLICK, 2009). Através das formas narrativas, os profissionais falaram de si, das suas práticas, trajetórias, crenças e experiências laborais e de formação. Desse modo, foi permitido dar VOZ aos assistentes sociais entrevistados (DUBAR, 2012).

As entrevistas semiestruturadas foram empregadas como um guia, por meio de roteiro pré-elaborado; no entanto, permitiram o surgimento espontâneo de outras questões sobre os objetivos pesquisados. Estas enfocaram as experiências biográficas, possibilitando o contato com a realidade vivida pelos sujeitos. Como procedimento metodológico, as entrevistas são um método específico de coleta de dados, enfocando as experiências biográficas e permitindo ao pesquisador estudar tópicos e contextos mais amplos. A entrevista pode, ainda, ser considerada como uma técnica de pesquisa por excelência na investigação social, de modo a proporcionar a obtenção de dados sobre os mais diversos aspectos da vida social, além de dados em profundidade acerca da vida do entrevistado (LAPERRIÈRE, 2008).

Já a técnica de entrevista narrativa foi empregada não no sentido restrito desse tipo de técnica qualitativa, mas indiretamente, com o objetivo de obter relatos baseados nas trajetórias biográficas, oferecendo espaço para que os entrevistados narrassem suas histórias com pouca ou nenhuma

\footnotetext{
${ }^{4}$ Dissertação de mestrado intitulada Eu nasci para ser assistente social: o trabalho em Serviço Social, profissionalização, identidade e gênero, apresentada em julho de 2014 no Programa de Pós-Graduação em Sociologia da Universidade Federal de Goiás, sob orientação do professor Dr. Jordão Horta Nunes (BOLZAN, 2014).

${ }^{5}$ A pesquisa contemplou todos os requisitos legais exigidos pelo Comitê de Ética da Universidade Federal de Goiás (UFG). Foram utilizados nomes fictícios para garantir a privacidade e confidencialidade dos participantes da pesquisa, resguardando sua identidade.
} 
intervenção da pesquisadora. As narrativas são um método específico para coleta de dados particularmente interessante na pesquisa qualitativa. Isto porque apresentam experiências mais profundas e detalhadas da vida do entrevistado, estimulando os sujeitos a narrarem questões de sua vida e pontos de vista que interessam à pesquisa (FLICK, 2009). Compreende-se as histórias de vida como construções sociais, ou seja, as narrativas fornecidas revelam as construções culturais da vida dos entrevistados (DUBAR, 2012).

Foram realizadas 15 entrevistas entre maio de 2013 e fevereiro de 2014, com 13 mulheres e dois homens entre 30 e 70 anos. As áreas de atuação desses profissionais são diversificadas: assistência social, saúde, Instituto Nacional do Seguro Social (INSS), Ministério Público (MP), Secretaria Municipal de Desenvolvimento Urbano (Semdus) e Organização Não Governamental (ONG). Os tipos de vínculos caracterizam-se por estatutários efetivos (município, Estado ou União), contratos por tempo determinado, cargo comissionado e trabalho voluntário.

A amostra constituída ${ }^{6}$ para a realização de entrevistas foi heterogênea, intencional e não probabilística, composta por profissionais de ambos os sexos, com idades variadas, tipos de vínculo/contrato de trabalho diferenciados, locais de trabalho distintos e características sociodemográficas diversas. Dessa forma, foram selecionados profissionais formados após o ano de 1993, utilizado como demarcador temporal, pois nesse período foi implementado um novo Código de Ética com novos parâmetros e referencial teórico, com orientação teórico-prática inspirada na tradição marxista, objetivando posicionar ética e politicamente os profissionais frente aos usuários das políticas públicas.

No entanto, houve exceções. Duas entrevistas de pessoas que se formaram em 1984 e em 1990 foram mantidas. Isto porque o perfil destas entrevistadas foi extremamente interessante para a pesquisa: uma contribuiu para a fundação de um grupo feminista em Goiânia; a outra, por sua vez, participou de várias gestões do Conselho Regional de Serviço Social (Cress) em anos anteriores. O ano de 1993 também marca a aprovação da Lei Orgânica de Assistência Social (LOAS - Lei no 8.742/93), a regulamentação da profissão sob a Lei no 8.662/93 e a implementação de Novas Diretrizes Curriculares para os cursos de Serviço Social durante a década de 1990. Ou seja, estes são os maiores marcos legais que atuam diretamente sobre o exercício profissional, e sintetizam a busca da categoria para transformar e renovar a atuação da profissão com base em parâmetros legais.

As entrevistas foram realizadas observando o critério de "saturação teórica", ou seja, as informações foram coletadas até perceber que houve

\footnotetext{
${ }^{6}$ As primeiras seis profissionais foram selecionadas aleatoriamente durante a XXX Semana da/o Assistente Social, realizada em maio de 2013. Outros contatos foram indicados por uma professora da UFG e por uma professora da PUC-GO. Por fim, outros profissionais foram indicados pelos próprios entrevistados, por meio da estratégia "bola de neve" (FLICK, 2009), fazendo com que um caso levasse a outro.
} 
saturação das categorias, quando não apresentaram dados adicionais de maior relevância (FLICK, 2009). Desse modo, a amostragem foi constituída gradativamente durante a fase de coleta, entre maio de 2013 e fevereiro de 2014. O prosseguimento da amostragem ocorreu de acordo com a relevância dos casos e não conforme a representatividade do número de assistentes sociais registrados no Cress. Nessa situação, Flick (2009, p. 124) sugere que sejam integrados ao estudo os casos da amostragem que se apresentam "extremos ou desviantes", pois essa seleção permite chegar a uma compreensão do campo a partir de determinados casos que se distinguem entre si. Caracterizando, assim, as extremidades desse campo e revelando "O alcance da variação e da diferenciação no campo".

\section{O trabalho emocional no setor de serviços}

A sociologia das emoções é um campo de estudos novo para o Serviço Social. Mesmo em extensa busca on-line pelos maiores sites de publicação científica, não se encontra nenhum trabalho, periódico, artigo científico, tese ou dissertação que aborde a profissão pelas lentes da sociologia das emoções.

Segundo Hochschild (2003, p. 7), "o trabalho emocional (emotional work) consiste na administração do sentimento para criar uma fachada facial e corporal publicamente observável". Isso significa que determinados trabalhos necessitam administrar as emoções, inibindo-as, induzindo-as ou moldando-as de acordo com as regras do sentimento estabelecidas socialmente, criando, assim, uma fachada publicamente observável, como o sorriso estampado das aeromoças ou a expressão séria de um policial. Os empregados do setor de serviços são chamados a manifestar constantemente suas emoções, uma vez que estabelecem relações com os clientes (HOCHSCHILD, 2003).

Na esfera pública, o trabalho emocional tem um valor de troca. Torna-se uma mercadoria comercializada, ainda que, no espaço privado ${ }^{7}$, esses atos emocionais tenham apenas um valor de uso. Ao desempenhar o trabalho emocional, o agente atua superficialmente (surface acting), como ao sorrir para demonstrar gentileza e receptividade. No entanto, também atua em profundidade (deep acting), refletindo e transformando seus sentimentos para justificar subjetivamente a expressão de sinais corporais que manifestam objetivamente o trabalho emocional.

O gerenciamento das emoções de maneira superficial se caracteriza pela atuação na mudança da expressão sem modificar os sentimentos internos. Apesar disso, quando se torna necessário atuar em profundidade,

\footnotetext{
${ }^{7}$ Hochschild (2003) designa como administração das emoções (emotion management) ou operacionalização das emoções (emotion work) a atividade do trabalho emocional no espaço privado.
} 


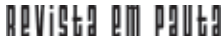

\} TRABALHO EMOCIONAL E GÊNERO - BOLZAN, D. P. \}

DOI: $10.12957 /$ rep.2015.21054

as emoções constituem um esforço de mudança desses sentimentos para conseguir exibir o que é requerido, atingindo, constantemente, o bemestar no trabalho e a subjetividade do trabalhador (HOCHSCHILD, 2003).

O TE apresenta três características essenciais: o contato direto e constante com o público (face a face ou voz a voz); o contato com o estado emocional do cliente/usuário, interagindo e produzindo um estado emocional no outro (gratidão, emoção, alegria, satisfação, medo etc.) e influência da administração/gerência por meio de treinamento e supervisão, exercendo controle sobre as atividades dos empregados (PADILHA, 2013). No caso do Serviço Social, certamente as duas primeiras características se evidenciam, pois o contato com os usuários frequentemente ocorre, inclusive em seus próprios domicílios ou vizinhanças da moradia. Entretanto, o controle administrativo ou no limite, coercitivo, não ocorre, a não ser em casos específicos.

Por um lado, as competências hoje atribuídas e reconhecidas na ocupação priorizam a implementação de políticas públicas e programas sociais como dever do Estado e direito de todo cidadão. Contundo, ainda persiste a dimensão "assistencialista" que caracterizou a ocupação no passado. Esta corresponde a uma representação social ligada ao cuidado (care), valorizando social e psicologicamente a interação presencial e, no limite, até afetuosa com os usuários. Na Lei ${ }^{\circ} 8.662 / 93$, por exemplo, que institui as atribuições privativas para o exercício profissional de assistentes sociais, a dimensão do "cuidado" está presente na competência de encaminhar providências, prestar orientação social a indivíduos e grupos, orientandoos na identificação de recursos e no uso destes, no atendimento e na defesa de seus direitos, estabelecendo relações diretas e constantes com os usuários do Serviço Social (BRASIL, 1993).

$\mathrm{Na}$ assistência social, a criação e o fortalecimento de vínculos são uma proposta do Ministério do Desenvolvimento Social e Combate à Fome (MDS) e faz parte da Proteção Básica, compondo serviços dos Centros de Referência de Assistência Social (Cras). Segundo o MDS (2015, n.p.), esses serviços "previnem a institucionalização e a segregação de crianças, adolescentes, jovens e idosos e oportunizam o acesso às informações sobre direitos e participação cidadã". Compondo a equipe multidisciplinar dos Cras e implementando tais programas, os assistentes sociais estão em constante envolvimento com usuários, famílias e comunidades. Não raro, isto implica em relações próximas e até pessoais com os mesmos.

Além disso, as relações estabelecidas entre profissional e usuários têm grande importância para as instituições empregadoras, geralmente órgãos públicos. Ou seja, a qualidade dos atendimentos e das relações estabelecidas entre profissional e usuários favorece a representação positiva da instituição, legitimando suas políticas e reforçando o poder estatal. Nessa relação, é requerido maior dispêndio de TE pelo profissional de Serviço Social, mediando os interesses e objetivos entre instituição e usuários. 


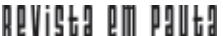

\} TRABALHO EMOCIONAL E GÊNERO - BOLZAN, D. P. \}

DOI: $10.12957 /$ rep.2015.21054

Segundo Glória Bonelli (2003), as ocupações que lidam diretamente com o público e estão em posições subalternas na hierarquia das profissões são as que mais incorporam TE. Assim, devemos pensar o trabalho das emoções numa perspectiva de gênero, uma vez que o TE "é mais acentuado entre as mulheres do que entre os homens" (BONELLI, 2003, p. 357). Determinados grupos ocupacionais estão mais suscetíveis a realizar $\mathrm{TE}$, tais como enfermeiras, assistentes sociais, pedagogas, comissárias de bordo e profissionais de venda direta. Essas profissões são marcadas por uma estreita separação entre as características pessoais e sua adequação ao trabalho, transformando traços como aparência, idade, educação, gênero e raça em potencial produtivo, "de tal forma que características e competências individuais são a condição mesma da empregabilidade" (SORJ, 2000, p. 30).

Não obstante, desde a criação do curso de Serviço Social em Goiás, em 1957, reproduz-se uma "imagem" de Serviço Social baseado no "modelo" de assistente social vinculada à "ação benéfica", como especialização técnica apta a trabalhar "junto aos empregados" e "desajustados sociais" (MIGUEL, 1989, p. 74). Além disso, a Escola de Serviço Social do Centro-Oeste trazia um caráter inteiramente religioso ao ensino, baseado nos princípios católicos, sendo fundada e financiada sob a égide da Igreja. A Escola buscava constantemente apoio moral e financeiro ao Estado e às organizações da sociedade civil, como a Legião Brasileira de Assistência (LBA). Dessa maneira, fazia-se uma forte vinculação da assistência social às mulheres, acionando para o campo dessa política habilidades e qualidades representadas na figura feminina, como cuidado, amor ao próximo, paciência e sensibilidade. Portanto, historicamente e ao longo do processo de profissionalização, o Serviço Social tornou-se uma ocupação feminizada, encampando todos os significados, atribuições e valores que a mulher ocupa na sociedade.

Há uma clara divisão sexual do trabalho emocional, concebida a partir de uma divisão entre a emoção (feminino) e o racional (masculino). Assim, são atribuídas às mulheres tarefas que demandam simpatia, ternura, paciência, bondade, gentileza, sensibilidade, intuição etc. Aos homens cabem as tarefas que exigem racionalidade, agressividade, dureza, aspereza, frieza etc. Até o ato de chorar é sexuado, socialmente construído sob a ideia de que "homem não chora", cuja expressão é, inclusive, letra de recente música brasileira. No mundo do trabalho emocional, essa divisão sexual manifesta-se concretamente nas orientações profissionais, guiando os homens para os trabalhos mais "duros", ao passo que as mulheres têm mais chances para os trabalhos que exigem "sua amabilidade" (HOCHSCHILD, 1983).

Nesse sentido, o trabalho deve ser pensado como uma relação social que considera classe, gênero e raça como elementos constitutivos. É preciso desvendar a pretensa neutralidade da categoria trabalho, mostrando 


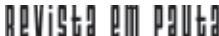

\} TRABALHO EMOCIONAL E GÊNERO - BOLZAN, D. P.

DOI: 10.12957/rep.2015.21054

suas características sexuadas e situando as suas relações necessariamente num contexto social e histórico. Além disso, a problemática de gênero nos permite pensar contra a ideia dominante de uma classe trabalhadora homogênea, o que, ao contrário, nos leva a pensar sua heterogeneidade, dando evidência aos marcadores de diferença e desigualdade na sociedade, como raça, sexo, nacionalidade e idade.

A categoria gênero explica as relações desiguais entre os sexos como relações sociais, culturais, políticas e econômicas (re)produtoras dessas desigualdades, legitimando-as e naturalizando-as. Cabe ressaltar que estas relações desiguais são estabelecidas historicamente com base em construções culturais e sociais que diferenciam e hierarquizam os sexos. Ou seja, essa categoria questiona o lugar social e cultural ocupado pela mulher, lugar esse construído hierarquicamente como uma relação aparentemente natural de poder entre os sexos. Além disso, aborda a dimensão social, cultural e material da desigualdade sexual.

A articulação entre TE e gênero faz com que trabalhos que exigem maior grau de expropriação das emoções sejam geralmente preenchidos por trabalhadoras, afirmando que as disposições emocionais fazem parte das próprias condições de trabalho. As diferenças entre os sexos, criadas desde a socialização dos indivíduos, ganham concretude na divisão sexual do trabalho, atribuindo às mulheres profissões que impõem uma sobrecarga emocional mais pronunciada (SOARES, 2013).

Em vários casos, o gerenciamento laboral de emoções está relacionado ao reconhecimento e valorização cultural de certos estereótipos, como o da "família tradicional" e seus papéis, como o de homem que é "provedor", ligado à esfera pública, e a mulher voltada ao trabalho reprodutivo e doméstico, bem como os valores a ele associados.

No caso das comissárias de voo pesquisadas por Hochschild, percebe-se que, no contexto histórico dos anos 1960, o conjunto de valores e regras da família tradicional foi adaptado com sucesso para as atividades das aeromoças. Nos treinamentos ministrados por uma das empresas pesquisadas, às aeromoças e comissários empregava-se a analogia do "lar", conduzindo as funcionárias a se relacionarem com os passageiros assim como se relacionariam com convidados numa reunião familiar, em suas próprias casas (HOCHSCHILD, 2003, p. 105). Contudo, esse tipo de analogia sofreu transformações com o desenvolvimento da aviação comercial e o aumento do número de passageiros, bem como com a acessibilidade do serviço a estratos de menor poder aquisitivo. Com a criação de linhas com trajetos menos extensos, os voos tornam-se mais curtos para os clientes, enquanto as jornadas de trabalho tornaram-se mais longas para as comissárias, com número maior de passageiros a serem atendidos.

Assim, as representações sociais sobre a família tradicional e os vocabulários de motivações a elas associados se modificaram com o aumento do ingresso das mulheres na esfera pública do trabalho externo, acarretando 
mudanças no trabalho emocional, em nível privado e público. As trabalhadoras do sexo feminino sofrem processo análogo não somente no trabalho de comissários de voo, mas no setor de serviços em geral. Essas alterações nem sempre se coadunam aos interesses da empresa ou instituição, podendo redundar em problemas na interação com os usuários, descontinuidades no envolvimento ocupacional e até consequências para a saúde, como estresse, estranhamento de si e perda da capacidade de sentir. Por sua vez, o TE pode provocar grande prejuízo ao bem-estar de trabalhadores pelo enorme desgaste de fingir o que não se sente (HOCHSCHILD, 1983).

\section{O trabalho das emoções no Serviço Social}

O trabalho emocional torna-se, em muitas ocupações, uma dimensão do trabalho, sendo desempenhado tão rotineiramente que pode ser considerado no mercado como uma commodity (NUNES, 2011; HOCHSCHILD, 1983). No trabalho em serviços exige-se do trabalhador muito mais do que esforço físico: as interações são altamente demandantes de esforço emocional. Muitas vezes, o que se compra é a própria relação que se estabelece, como nas instituições de ensino-aprendizagem. Dito de outra forma, "o próprio trabalhador é parte do produto que está sendo oferecido ao cliente" (SORJ, 2000, p. 30).

A análise das entrevistas permite perceber que, nos espaços ocupacionais, o cotidiano dos assistentes sociais e as suas demandas são envoltas por componentes emocionais que exigem um alto grau de trabalho emocional: violência doméstica, desigualdades sociais, extrema pobreza, trabaIho doméstico, abuso sexual e moral, direitos reprodutivos (gravidez, aborto), planejamento familiar, disputa de guarda, dependência química, entre outros. Os relatos seguintes expõem as principais demandas que exigem TE das assistentes sociais:

Como eu trabalho com vítimas de violência, eu não perdi a capacidade de ficar indignada com a crueldade que as pessoas são capazes. Principalmente a violência sexual contra a criança, quando ela é praticada pelo padrasto, pelo tio, isso ainda mexe comigo. (Elisa, 38 anos, estatutária, solteira).

Aqui são todas, porque são vítimas de violência, crianças, né; muitas vezes é violência intrafamiliar. A gente faz o atendimento e busca garantir todos os direitos, porém, eu não gostaria de estar nesse programa, isso mexe muito comigo [...] são jovens, são crianças que vêm pro atendimento, são de baixa renda [...] vêm em sol ou chuva pra ter o atendimento. (Laura, 43 anos, contrato por tempo determinado, casada). 
Olha, [...], por exemplo, mãe solteira que tem dois, três filhos, e ela que resolve tudo, que dá alimento, é pai e é mãe, isso me emociona muito, eu fico emotiva com isso porque eu sei que ela tem que ir pro trabalho e fica entre a cruz e a espada. Ela fica pensando no filho que pode tá usando droga. Ou uma mãe que tem uma filha pequena, não tem com quem deixar, é só ela e as crianças; a mãe tá se matando e chega em casa, vai lavar a roupa, vai preparar a comida pra deixar pronta pro outro dia. Isso é o que mais acontece. (Luiza, 53 anos, estatutária, casada).

Historicamente, a oposição entre emoção e racionalidade faz parte da cultura ocidental. Durante muito tempo acreditou-se que era possível separar razão e emoção na esfera do trabalho; isso faria com que o trabalhador fosse mais eficiente e produtivo aos interesses capitalistas. Essa visão, ainda existente, torna heterogêneo e simplifica o trabalho, subestimando os efeitos das emoções, inclusive sob a saúde do trabalhador. No entanto, como atividade humana, o trabalho "é cenário de (re)produção de diferentes emoções": as pessoas criam relações, emocionam-se com uma promoção, sentem medo de perder o emprego ou de sofrer um acidente etc. (SOARES, 2013). Essas relações estabelecidas no ambiente de trabalho envolvem emoções e influenciam no processo de construção das identidades sociais.

Pensando na possibilidade de não se envolver emocionalmente no trabalho e na tentativa de separar o racional do emocional, Pedro (50 anos, contrato por tempo determinado, casado) expõe: "a gente acha que com algum tempo vai conseguir, mas não consegue não". Alice afirma tentar manter-se distante do envolvimento com o usuário, mas não consegue e se diz admiradora de profissionais que conseguem tal distanciamento:

É difícil lidar com as dificuldades dos outros, né, não tem como você não se envolver. A gente tenta, mas tem situações que não tem como você não se fragilizar com a vivência do outro. Então há um pouquinho [de estresse] porque você lida com as diferenças, com as dificuldades do outro, e isso traz uma certa angústia. Eu fico admirada daquela [profissional] que fica isenta de tudo, eu admiro, mas eu, eu não consigo. (Alice, 42 anos, contrato por tempo determinado, casada).

O comprometimento emocional para Júlia é inseparável do seu modo de ser assistente social:

Me admira quando as colegas falam que dão conta de fazer o atendimento e ficar bem, depois nunca mais pensar naquilo. Eu já estive na ponta, decidi parar de trabalhar, era com violência sexual. Eu trabalhei dois anos e no meu limite, eu não dou conta, não tenho estrutura emocional pra isso. Porque cheguei ao ponto de terminar o atendimento e sair pro banheiro e chorar. Eu me colocava no lugar daquela família [...]. Eu vejo o quanto me fragilizou emocionalmente a ques- 
tão da violência sexual. Hoje, quando aqui recebe uma denúncia e é uma coisa mais grave, eu olho e me faz mal. Eu pessoalmente tenho o comprometimento emocional sempre (Júlia, 36 anos, estatutária, união estável).

Para Telma, assistente social do INSS, casos de concessão de BPC e casos de requisição de pensão para mulheres idosas exigem mais trabalho emocional, uma dimensão do trabalho em Serviço Social que, segundo a profissional, faz parte de sua identidade. O relato chama atenção para o fato de que muitas mulheres não alcançam os benefícios da previdência, seja por se encontrarem na informalidade ou em vínculos sem direitos trabalhistas, como ocorre no serviço doméstico, seja por sequer possuírem documentos pessoais, especialmente as que residem em áreas rurais. Essas mulheres estão, portanto, cotidianamente procurando a assistência social em busca de condições de sobrevivência de suas famílias.

Muitos casos e o BPC, né, porque você lida mesmo com a maioria naquela condição de invisibilidade, de risco, e você vê assim que a situação deles é muito precária. Mas você sabe que a deficiência daquela criança não vai passar na perícia médica e não vai ser concedido [o benefício]. E também é muito injusto com a maioria das mulheres idosas; o marido é aposentado e ganha um salário mínimo, aí ela faz o requerimento [do benefício] e o BPC é negado por causa da aposentadoria do marido [...]. Eu vejo também uns casos muito tristes de pensão, né. Aquelas mulheres dependentes do marido que trabalha e ele não é segurado, ele falece num acidente e ela se encontra naquela situação, viúva, com vários filhos, e ela vem aqui e não tem direito à pensão [...]. Você tenta não se vincular a essa pessoa, até pra sua própria saúde mental, mas tem muitos casos que é inevitável, não tem como, até porque já faz parte da nossa identidade, né, é muito difícil. (Telma, 38 anos, estatutária, casada).

Alice ressalta que o próprio relacionamento com o usuário, a capacidade de escuta e as emoções trazidas produzem e exigem o gerenciamento do TE:

Aí me emociona porque tem [...] tem vezes que o usuário só quer ser ouvido, e isso também é muito importante, porque a partir do momento que ele chega na unidade, que você recebe, que você faz a primeira acolhida, que ele senta na sua frente e faz assim "ai!", você vê que você já acolheu bem aquele usuário. E ali ele tá aberto a tudo, você entra no seio da família, você entra na intimidade daquele usuário, ele traz coisas assim que, querendo ou não, não tem como não se emocionar. (Alice, 42 anos, contrato por tempo determinado, casada).

De uma parte, o usuário chega ao Serviço Social com um conjunto de expectativas de natureza material, emocional e psicológica advindas de situações de carência material, violação de direitos, empobrecimento, abuso 


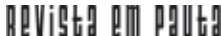

\} TRABALHO EMOCIONAL E GÊNERO - BOLZAN, D. P. \}

DOI: $10.12957 /$ rep.2015.21054

sexual etc. De outra, o assistente social, ao mesmo tempo, apresenta-se com uma conformação emocional e psicológica também complexa, tendo que gerir e mediar a relação daquele indivíduo com o Estado. Essa relação de proximidade faz com que a assistente social tenha acesso privilegiado a informações dos usuários e desenvolva ainda mais o TE, tornando a prática profissional um exercício constante no sentido de gerenciar, além das suas próprias emoções, as emoções do outro, como é percebido na fala de Telma: "Na previdência, como a demanda é menor, a gente consegue dar o atendimento mais qualificado, né. Então você conhece melhor e se envolve mais com as pessoas, com as famílias que a gente acompanha, então acaba que me afeta, né".

É também importante mencionar que o trabalho emocional não é por si só um motivo de estresse, exaustão emocional e esgotamento, mas relaciona-se a outros fatores, como condições de trabalho desfavoráveis, jornadas longas e pouca experiência e tempo de trabalho na atividade de interação com clientes. Quanto maior for a autonomia, a possibilidade de ser autêntico nas interações e o reconhecimento no trabalho, significativamente menor será o desgaste emocional. Isso demonstra que não é o trabaIho emocional em si que esgota o trabalhador, mas o conjunto de fatores, exigências afetivas e condições em que o trabalho emocional é realizado no contexto da organização (VILELA; ASSUNÇÃO, 2007).

As entrevistas expõem que o desgaste do ambiente de trabalho e o esforço emocional e físico, além das condições inadequadas de trabalho, trazem consequências para a saúde, tornando frequentes as queixas de esgotamento, cansaço e estresse, entre outras patologias. Este é o caso de Pedro, que ficou dois anos afastado do mercado de trabalho para tratamento de saúde: "inclusive eu fui vítima do estresse, eu adoeci. Estresse e depressão". Em outros casos, há relato de "mal-estar, desânimo, que é o que a gente vê em todos" (Laura). Problemas de saúde também já afetaram Luiza: "eu tive um problema na coluna e tive LER $^{8}$ na Casa da Acolhida", porque a gente escrevia demais e eu escrevo muito".

No caso de Telma, as consequências para a saúde parecem ter sido mais graves, como relata: "eu adoeci, eu comecei a fazer terapia e faço tratamento psiquiátrico até hoje, e tomo remédio pra depressão até hoje. Só o [remédio] da síndrome do pânico que o médico tirou, mas hoje eu consigo trabalhar melhor, antes me afetava mais, hoje já melhorou bastante".

Todos os assistentes sociais da pesquisa relatam que as exigências institucionais, a burocracia excessiva e as condições precarizadas de trabalho geram sobrecarga e desgaste emocional, consequentemente demandando TE:

\footnotetext{
${ }^{8}$ Lesão por Esforço Repetitivo (LER), em inglês Repetitive Strain Injury.

${ }^{9}$ Criada em 2007, a Casa de Acolhida Cidadã tem como objetivo abrigar, temporariamente, famílias e adultos em situação de rua, aqueles que estão em trânsito, ou seja, migrantes e imigrantes, e pessoas que recebem alta hospitalar e não possuem vínculo familiar identificado no município de Goiânia.
} 
Olha, aqui é um trabalho que exige muito, que absorve muita energia da gente, aqui é atendimento ao adolescente infrator [...]. Aqui é demais o trabalho, eu falo aqui, mas não é só aqui não, isso é em todas as unidades; a exigência é muito grande, mas as condições de trabaIho não são boas, não temos nem material pra trabalhar. Até uma coisa simples, uma pasta, um prontuário, tudo é muito burocrático, a carga horária é excessiva porque você tem que mergulhar mesmo no trabalho e é muita cobrança de relatório. Pela lei nós não podemos assistir mais de vinte adolescentes, mas eu estou com trinta e quatro adolescentes, então isso sobrecarrega muito, tem coisa que você não quer levar pra casa, mas você leva. (Luiza, 53 anos, estatutária, casada).

A própria dinâmica de funcionamento do setor público pode gerar situações de estresse, como pontua Júlia: "Muito estresse! E pelo salário a gente não tem motivação [...]. O ambiente e a profissão são muito estressantes. Principalmente no serviço público. Tudo é pra ontem. Tudo é pra apagar fogo. Então isso deixa a gente muito mal".

Por outro lado, as relações sociais estabelecidas fora do ambiente de trabalho oferecem suporte externo (relações familiares, amorosas, amizades) e são fatores protetores contra a exaustão emocional, bem como aliviam o estresse emocional. Os entrevistados descrevem a prática de atividades físicas, como corrida, caminhada e academia, além de relato de trabalho manual com plantas, viagem em final de semana para chácara e cultos religiosos como suavizadores das tensões emocionais e físicas geradas no trabalho.

A apropriação do trabalho emocional, no que tange à manipulação emocional por exigência institucional, aparece no relato de uma profissional. Ela demonstra que há uma separação entre o significado dos sentimentos exigidos pela instituição e de seus próprios sentimentos e interpretações, exemplificando sua percepção de incongruência entre a emoção sentida e a exigida:

Lá as pessoas vivem muito de aparência, então, assim, o tratamento que pedem para com os usuários, inclusive, é um tratamento que eles querem que seja tratamento paternalista, de política assistencialista. Eles pedem para você ter esse tratamento, mas não é por conta do usuário, é muito para deixar a impressão da equipe da primeira dama, a equipe da primeira dama é a melhor equipe, é uma equipe humanizada, mas é aquele humanismo conservador. Então, assim, não é a questão do usuário, do usuário se sentir bem; é a questão do usuário dizer que foi na Secretaria (de Assistência Social) e ele foi muito bem atendido pelo pessoal da primeira dama. Então ninguém tá preocupado com o usuário, todo mundo tá preocupado é em manter seu poder e as relações de poder. (Ana, 30 anos, estatutária, união estável). 


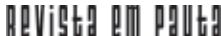

\} TRABALHO EMOCIONAL E GÊNERO - BOLZAN, D. P.

DOI: $10.12957 /$ rep.2015.21054

Como observa Bonelli (2003, p. 358), o trabalho emocional é um gerenciamento intermitente das emoções, uma forma consciente de como "os seres humanos atuam para suprimir a distância entre o que estão sentindo e o ideal que têm do que deveriam sentir". É justamente uma atuação superficial (surface acting) que se pode observar no trecho ilustrado anteriormente, ou seja, uma divergência entre a "aparência" que o usuário deve ter do serviço e a simulação que a instituição exige da profissional por intermédio da manipulação da emoção. Entretanto, a assistente social parece apresentar uma leitura crítica e consciente sob a dissonância entre o componente político envolvido na simulação de sentimentos e a autenticidade de seus próprios sentimentos enquanto profissional. Segundo Padilha (2013), esse é um aspecto fundamental do trabalho emocional, no qual o trabalhador vende a imagem da empresa/instituição e sua marca/serviço, e nesse processo estabelece relações com os clientes/usuários.

Os relatos apresentados evidenciam que, no Serviço Social, as emoções são administradas em profundidade (deep acting) e são tão rotineiras que chegam a ser interiorizadas e inseparáveis do cotidiano, mesmo quando se tenta manter certa distância e racionalidade. Isto contribui para que o trabalho emocional se constitua como parte da identidade profissional.

O TE orientado por gênero também deixa suas implicações no Serviço Social, como se evidencia no relato de Pedro, que percebe uma diferença no comportamento dos "meninos" quando são atendidos por um profissional do sexo masculino: "Eu acho que na questão de abordagem, tem hora que tem que ser forte. Então aí que entra a questão de ser homem, a questão do menino te ouvir sabendo quando é pra tomar uma atitude, ele vai tomar de uma forma diferente da mulher". Soares (2013) observa que o TE está implícito na divisão sexual do trabalho, sendo que os homens devem externar atitudes que exijam um comportamento mais agressivo, rude, duro, frio etc. Esses estereótipos associam os homens ao "campo do racional, do público e da produção, enquanto as mulheres são associadas ao campo do emocional, do doméstico e da reprodução" (SOARES, 2013, p. 164).

As regras de sentimentos são construídas culturalmente, fazendo parte da tradição e da socialização. Soares (2013) observa que, durante a socialização, até o ato de chorar torna-se sexuado. Os homens são educados para não chorar, reprimir emoções e não demonstrá-las em público. "No mundo da virilidade, as lágrimas são associadas à fraqueza, à feminilidade, à covardia" (SOARES, 2013, p. 167). Por outro lado, os estereótipos de gênero permitem que a mulher exponha suas emoções, relacionando-as à sua "natureza biológica", à fragilidade e à docilidade. Portanto, a cultura e a socialização têm papel crucial na determinação de quem pode expor ou inibir suas emoções, definindo como, onde e por que elas devem e podem aparecer. 
No setor de serviços, os códigos e regras de conduta sobre os sentimentos encontram-se subentendidos no trabalho emocional como componente intrínseco ao trabalho feminino. As ocupações no setor de serviços estão relacionadas ao tradicional papel ocupado pelas mulheres no âmbito doméstico. São atividades vistas como menos qualificadas, geralmente baseadas em atributos e "qualidades" femininas, como o amor, o cuidado, a simpatia e a paciência.

No rol das profissões do setor de serviços, o Serviço Social configurou-se desde seu surgimento como campo complexo e contraditório para as mulheres. Isto porque representou uma conquista feminina, embora limitada, no espaço ocupacional do mundo do trabalho assalariado, caracterizando-se como um nicho feminino no mercado de trabalho. No entanto, a profissão ainda não ocupa um lugar valorizado social e financeiramente frente à hierarquia das profissões, ratificando a divisão sexual do trabalho e permanecendo uma profissão vinculada a valores associados ao feminino, mesmo nos dias atuais.

\section{Considerações finais}

No campo do trabalho emocional, o Serviço Social configura-se como uma profissão que administra as emoções em "atuação profunda" (deep acting), ou seja, um gerenciamento que engloba todo o ser, uma vez que esses profissionais não conseguem separar as emoções do trabalho cotidiano (HOCHSCHILD, 1983). Isto faz com que até sua subjetividade seja engajada no trabalho, "misturando muito mais as fronteiras entre o público e o privado" (PADILHA, 2013, p. 187).

A interseção entre TE e gênero mostra a persistência do Serviço Social como nicho de trabalho feminino. Demonstra, ainda, a permanência da divisão sexual do trabalho, hierarquizando as ocupações no mundo do trabalho, valorizando ou não certas profissões e criando "guetos" ocupacionais, como no Serviço Social, Enfermagem e Pedagogia. A permanência da marca de gênero subsiste no Serviço Social, reproduzindo uma concepção sexuada de exercício profissional. Portanto, reconhecer que o trabalho possui, além das dimensões físicas e cognitivas, outras dimensões, como as emocionais, sexuais e relacionais, é fundamental para compreender o trabalho e suas múltiplas significações que interagem reciprocamente.

A gestão emocional é um aspecto importante do trabalho no Serviço Social, uma vez que este é realizado em constante interação com os usuários. As entrevistas comprovam que assistentes sociais realmente vivenciam emoções em grau considerável e alteram o gerenciamento emocional nas diferentes demandas, competências e situações relacionadas à profissão. As emoções são tão cotidianas no Serviço Social que se tornam parte da identidade profissional dos assistentes sociais. Isso acontece porque, 


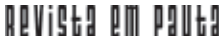

\} TRABALHO EMOCIONAL E GÊNERO - BOLZAN, D. P.

DOI: 10.12957/rep.2015.21054

no trabalho em serviços, "é impossível separar claramente o trabalhador, o processo de trabalho e o produto" (PADILHA, 2013, p. 190). Entretanto, não se pode afirmar, a exemplo do que ocorre em outras ocupações no mundo dos serviços, que é verificável uma exploração predatória, ou até mesmo uma expropriação do trabalho emocional, por parte das instituições empregadores, pois a maior parte dos trabalhadores do Serviço Social está vinculada a instituições públicas, o que não garante condições satisfatórias de trabalho.

Compete ressaltar que os resultados apresentados não são generalizáveis para toda a categoria, contudo, admite-se que a amostra possa, de alguma forma, representar as peculiaridades e características no que diz respeito ao trabalho emocional e à construção identitária. Ressalta-se, portanto, a necessidade de uma cuidadosa reconstrução dos conceitos de trabalho emocional e gerenciamento emocional, com suporte na pesquisa empírica e reelaboração de um instrumental teórico-metodológico adequado à análise do Serviço Social no Brasil. Levando, desse modo, em conta sua trajetória histórica e as diferentes formas de organização do trabalho, de contratação e de atuação ocupacional em localidades distintas.

Por fim, espera-se que a aproximação da Sociologia das Emoções com o Serviço Social possa ser recebida pela categoria como aporte teórico capaz de instigar novas pesquisas e estudos para o Serviço Social, atingindo a própria categoria na autoavaliação e autorreflexão da profissão, considerando o campo das emoções como uma das diferentes dimensões e exigências do trabalho em Serviço Social, não menos importante que outras. 


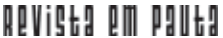

\} TRABALHO EMOCIONAL E GÊNERO - BOLZAN, D. P.

DOI: $10.12957 /$ rep.2015.21054

\section{Referências}

ALMEIDA, S.O.; NIQUE, W.M. Encantamento do cliente: compreendendo $o$ conceito e validando o constructo. In: ENCONTRO NACIONAL DA ANPAD, 28, 2004, Curitiba. Anais... Rio de Janeiro: ANPAD, 2004.

BOLZAN, D. de P. Eu nasci para ser assistente social: o trabalho em serviço social, profissionalização, identidade e gênero. 2014. Dissertação (Mestrado em Sociologia) - Universidade Federal de Goiás, Goiânia. 2014.

BONELLI, M. da G. Arlie Russell Hochschild e a sociologia das emoções. Cadernos Pagu, v. 21. 2003.

BRASIL. Lei 8.662, de 07 de junho de 1993. Brasília: Diário Oficial da República Federativa do Brasil. 1993.

COSTA, A.C.R.; FARIAS, S.A. Emoções e satisfação em compras on-line: o "Ser" é humano em ambientes intermediados por computadores?. In: ENCONTRO NACIONAL DA ANPAD, 28, 2004, Curitiba. Anais... Rio de Janeiro: ANPAD, 2004.

DUBAR, C. A construção de si pela atividade de trabalho: a socialização profissional. Cadernos de Pesquisa, Maranhão, v. 42, n. 146. 2012.

FLICK, U. Dados verbais. In: Uma introdução à pesquisa qualitativa. Porto Alegre: Bookman. 2004.

. Coleção pesquisa qualitativa. Porto Alegre: Artmed. 2009.

GOFFMAN, E. The presentation of self in everyday life. New York: Doubleday Anchor. 1959.

HOCHSCHILD, A. R. The managed heart: commercialization of human feeling. Berkeley: University of California Press. 1983.

. The commercialization of intimate life: notes from home and work. Berkeley: The University of California Press. 2003.

KOURY, M. Pela consolidação da sociologia e da antropologia das emoções no Brasil. Revista Sociedade e Estado, v. 29, n. 3, set./dez. 2014.

LAPERRIÈRE, A. Os critérios de cientificidade dos métodos qualitativos. In: VV. AA. A pesquisa qualitativa. Enfoques epistemológicos e metodológicos. Petrópolis: Vozes. 2008.

LOBO, E. S. A classe operária tem dois sexos, trabalho, dominação e resistência. São Paulo: Brasiliense. 1991.

LUTZ, C. Engendered Emotion: gender, power, and the rethoric of emotional control in american discourse. In: LUTZ, C.; ABU-LUGHOD, L. (ed.). Language and the politics of emotion. Cambridge: Cambridge University Press. 1990. 


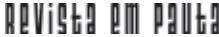

\} TRABALHO EMOCIONAL E GÊNERO - BOLZAN, D. P.

DOI: 10.12957/rep.2015.21054

MDS. Ministério do desenvolvimento social e combate à fome. Secretaria Nacional de Renda de Cidadania. 2015. Disponível em: <www.mds.gov.br> Acesso em: jun. 2015.

MIGUEL, W. L. O Serviço Social e a "promoção do homem": um estudo de ideologia. Goiânia: Editora UCG. 1989.

NUNES, J. H. A seu dispor! Identidade e interação no trabalho em serviços. In: A seu dispor! Sociologia do trabalho em serviços. Goiânia: Editora da PUC-Goiás. 2011.

PADILHA, V. A demanda por trabalho emocional diante do nojo: um estudo com trabalhadores de limpeza de shopping centers. In: LIMA, J. C. (org.). Outras sociologias do trabalho: flexibilidades, emoções e mobilidades. São Carlos: EduFSCar. 2013.

SAFFIOTI, H. Gênero e patriarcado: violência contra mulheres. In: A mulher brasileira nos espaços público e privado. São Paulo: Fundação Perseu Abramo. 2004.

SIMÕES, P. Assistentes sociais no Brasil: um estudo a partir das PNADS. Rio de Janeiro: E-papers Serviços Editorias Ltda. 2012.

SOARES, A. Como segredos: as lágrimas no trabalho. In: LIMA, J. C. (org.). Outras sociologias do trabalho: flexibilidades, emoções e mobilidades. São Carlos: EduFSCar. 2013.

SORJ, B. Sociologia e trabalho: mutações, encontros e desencontros. Revista Brasileira de Ciências Sociais, São Paulo: ANPOCS, v. 15, n. 43. 2000.

VILELA, L. V. de O.; ASSUNÇÃO, A. A. Trabalho emocional: o caso dos teleatendentes de uma central de atendimento. Cadernos de Psicologia Social do Trabalho, São Paulo, v. 10, n. 2. 2007.

Recebido em 31 de julho de 2015.

Aprovado para publicação em 21 de outubro de 2015.

DOI: 10.12957/rep.2015.21054

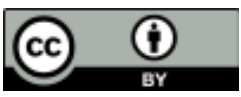

A Revista Em Pauta: Teoria Social e Realidade Contemporânea está licenciada com uma Licença Creative Commons Atribuição 4.0 Internacional. 